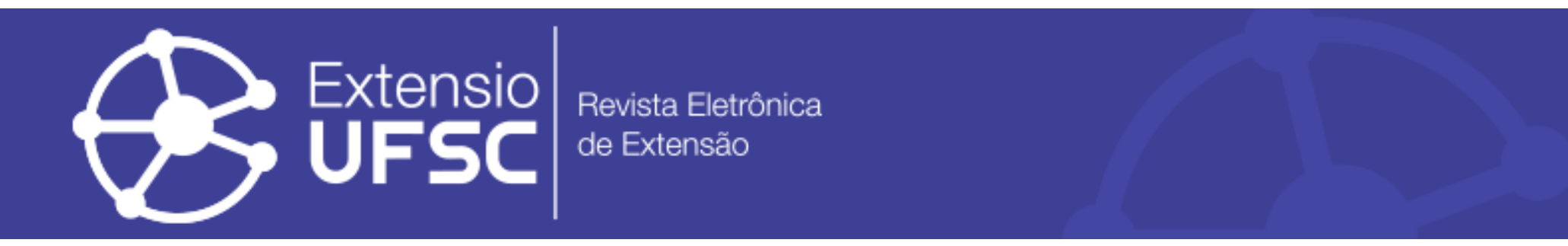

\title{
MOTUS - MOVIMENTO LITERÁRIO DIGITAL: DESPERTANDO E DIVULGANDO A LITERATURA NACIONAL
}

\author{
Aline Vieira de Mello \\ Universidade Federal do Pampa \\ alinevieiramello@gmail.com \\ Amanda Meincke Melo \\ Universidade Federal do Pampa \\ ammelounipampa@gmail.com \\ Bruno Braga Medeiros \\ Universidade Federal do Pampa \\ brunobragamedeiros@gmail.com
}

\section{Resumo}

A Motus - Movimento Literário Digital é uma ação vinculada ao programa de extensão Programa C, da Universidade Federal do Pampa (UNIPAMPA), que visa a incentivar a produção de obras literárias; intensificar o interesse pela literatura nos estudantes e cidadãos; e selecionar e publicar obras literárias inéditas, em Língua Portuguesa. A primeira publicação da Motus foi composta por contos e poemas sobre o tema "Liberdade de Expressão". Nesse contexto, este trabalho tem como objetivo relatar a experiência de organizar, produzir, e divulgar essa edição. Assim, são expostos os saberes relacionados às tarefas que envolveram seu desenvolvimento, como elas foram distribuídas entre as comissões que integram a Motus e, também, os processos de avaliação das obras literárias inscritas, diagramação e divulgação. Desse modo, tem-se um guia a fim de inspirar outras Universidades a contribuírem com a literatura nacional, semeando e enaltecendo escritoras e escritores amadores.

Palavras-chave: Literatura. Digital. Comunidade.

\section{MOTUS - DIGITAL LITERARY MOVEMENT: AWAKENING AND DISCLOSING NATIONAL LITERATURE}

\begin{abstract}
Motus - Digital Literary Movement is an action linked to the extension program called "C Program", from the Federal University of Pampa (UNIPAMPA), which aims to encourage the production of literary works; to intensify the interest in literature among students and citizens; and to select and to publish unpublished literary works written in Portuguese. Motus' first edition was composed by poems and short-stories around the theme "Freedom of speech". In this context, this work aims to report the experience of organizing, producing and publishing this edition. Therefore, the knowledge related to the tasks that involved its development and how they are distributed among the commissions that integrate Motus as well as the processes of evaluation of the inscribed literary works, the creation of the layout and disclosure is exposed. In this way, there is a guide to inspire other Universities to contribute to the national literature, sowing and praising amateur writers.
\end{abstract}

Keywords: Literature. Digital. Community.

\section{MOTUS - MOVIMIENTO LITERARIO DIGITAL: DESPERTANDO Y DIVULGANDO LA LITERATURA NACIONAL}

\section{Resumen}

La Motus - Movimiento Literario Digital es una acción vinculada al programa de extensión Programa C, de la Universidad Federal del Pampa (UNIPAMPA), que pretende fomentar la producción de obras literarias; intensificar el interés por la literatura en los estudiantes y los ciudadanos; y la selección y publicación de obras literarias en portugués. La primera publicación de Motus fue compuesta por cuentos y poemas sobre el tema "Libertad de Expresión". En este contexto, este trabajo tiene como objetivo relatar la experiencia de organizar, producir, y divulgar esa edición. Para ello, se exponen los saberes relacionados con las tareas que involucraron su desarrollo, como fueron distribuidas entre las comisiones que integran la Motus y, también, los procesos de evaluación de las obras literarias inscritas, diagramación y divulgación. De este modo, se tiene una guía para inspirar a otras Universidades a contribuir con la literatura nacional, sembrando y enalteciendo escritoras y escritores novatos.

Palabras clave: Literatura. Digital. Comunidad. 


\section{INTRODUÇÃO}

A Motus - Movimento Literário Digital é uma ação de extensão vinculada ao programa de extensão Programa C - Comunidade, Computação, Cultura, Comunicação, Ciência, Cidadania, Criatividade, Colaboração da Universidade Federal do Pampa (UNIPAMPA). A execução dessa ação é motivada por três grandes objetivos, sendo eles: o incentivo à produção de obras literárias; a intensificação do interesse pela literatura nos estudantes e cidadãos; e a seleção e publicação de obras literárias inéditas, em Língua Portuguesa.

A Motus foi planejada para incluir todo e qualquer cidadão que deseja divulgar ou ler obras literárias. Assim, para a sua primeira edição, Motus \#1 (VIEIRA, 2017), indivíduos de qualquer estado brasileiro puderam publicar sua obra, independentemente de idade, formação acadêmica e demais características. Por ser uma revista literária disponibilizada gratuitamente em formato digital, possui um público-alvo bastante abrangente.

A Motus \#1 é composta por contos e poemas sobre o tema "Liberdade de Expressão". O concurso foi construído digitalmente, a fim de facilitar a divulgação da proposta e atrair mais interessados. No total, 125 autores de 14 diferentes estados brasileiros e do Distrito Federal submeteram suas obras. Após uma rigorosa seleção, 20 inscritos foram selecionados, somando 11 poemas e 9 contos de 9 diferentes estados do Brasil e do Distrito Federal.

Além da produção literária contendo 20 obras diagramadas, a Motus \#1 foi, também, divulgada por meio de um aplicativo chamado QuizMotus (QUIZMOTUS, 2017). Esse aplicativo é um dos mecanismos utilizados para que a revista seja mais amplamente conhecida. A utilização do aplicativo é simples: ao responder três perguntas sobre o tema Liberdade de Expressão, uma poesia é escolhida e exibida ao usuário. Atualmente, o aplicativo se encontra na plataforma Play Store - loja virtual do Google para o sistema operacional Android (GOOGLE, 2017).

Este artigo tem como objetivo apresentar um relato sobre a experiência de criar a revista literária digital Motus e o processo de produção de sua primeira edição, abrangendo aspectos relacionados à formação das Comissões que integram a revista, o processo de avaliação das obras recebidas, a diagramação das obras selecionadas e, também, a divulgação da Motus \#1.

\section{MATERIAIS E MÉTODOS}

A ação de extensão Motus teve seu início no segundo semestre de 2016. Já o produto final de sua primeira edição foi liberado ao público em junho de 2017. Nesse ínterim, muitas 
atividades aconteceram. O planejamento da Motus envolveu duas comissões: Comissão Organizadora e Comissão Avaliadora.

A Comissão Organizadora foi constituída por doze discentes, uma docente e um técnicoadministrativo da UNIPAMPA. As tarefas dessa comissão foram, consecutivamente: a escolha do nome e do tema da primeira edição da revista; desenvolvimento do edital; planejamento do desenvolvimento gráfico; identidade visual da revista; divulgação da revista; e, por último, triagem das obras recebidas. Todas as tarefas foram debatidas durante reuniões de equipe. Em média, as reuniões aconteceram uma vez por semana, com duração de uma hora.

A primeira tarefa foi definir o nome da revista e o tema de sua primeira edição. Assim, reuniões foram executadas de forma democrática, onde cada membro da Comissão Organizadora sugeriu ideias tanto para o tema da primeira edição da revista, como também para o seu nome. Após três reuniões, o tema "Liberdade de Expressão" e o nome "Motus - Movimento Literário Digital" foram escolhidos.

A tarefa seguinte foi desenvolver o edital para o recebimento das obras literárias. O edital (EDITAL 01/2017, 2017) disserta sobre as condições de participação, os gêneros de obras literárias aceitos, o modo de envio da obra, a formatação da obra, o cronograma do concurso e a premiação dos selecionados. No total, o desenvolvimento do edital foi concluído em cinco reuniões.

Após a criação do Edital, o desenvolvimento gráfico da Motus começou a ser planejado. O software de diagramação que seria usado foi debatido e escolhido entre os membros da Comissão durante duas reuniões. Optou-se pela utilização do Scribus (SCRIBUS, 2016), um software livre que auxilia a tarefa de diagramação digital.

Dispondo do tema e do nome da revista, os membros que constituem a Comissão Organizadora debateram, durante uma reunião, sobre as cores, fontes e demais elementos que comporiam a identidade visual da Motus.

Após as onze primeiras reuniões, a Comissão Organizadora começou a divulgação da Motus, onde os membros da Comissão visitaram escolas públicas e privadas da cidade de Alegrete/RS e, também, divulgaram o edital, que continha as diretrizes para a submissão das obras, em diversas plataformas virtuais a fim de obter inscritos de variados estados. A divulgação da Motus foi concluída em cinco reuniões.

Posteriormente à divulgação e ao recebimento das obras participantes, a Comissão Organizadora iniciou a triagem das obras recebidas. Para a execução dessa atividade, a Comissão teve como base o conhecimento exposto no Edital no 01/2017 - seção 4, que disserta sobre o modo de formatação correto para a submissão da obra inscrita, como, por exemplo, fonte, 
espaçamento e margens. Todas as 125 obras recebidas foram conduzidas à triagem e, após cinco reuniões executando esse processo, 82 obras foram consideradas aptas à avaliação da Comissão Avaliadora. Sendo assim, a etapa de triagem eliminou 43 obras que não estavam de acordo com a formatação exigida no edital.

Observa-se que a triagem conduzida pela Comissão Organizadora teve seu foco apenas na formatação da obra recebida. Essa decisão foi acordada pelo fato de os integrantes que compõem a Comissão serem todos discentes de cursos da área de exatas, não tendo em sua formação educacional os saberes necessários à avaliação do conteúdo presente em obras literárias.

A avaliação do conteúdo das obras recebidas foi uma tarefa realizada exclusivamente pela Comissão Avaliadora. Essa Comissão foi composta por seis personalidades da cidade de Alegrete/RS que possuem experiência e competência na matéria examinada. Com o objetivo de inserir a UNIPAMPA - Campus Alegrete dentro da comunidade municipal, todos os avaliadores da Motus são Alegretenses, sendo três homens e três mulheres, com profissões diversas (um jornalista, um médico e quatro professores), mas todos com experiência na área da Literatura.

Após a tarefa de triagem, as obras aptas e a ficha de avaliação foram encaminhadas à Comissão Avaliadora, onde cada obra foi julgada por três avaliadores(as). Os critérios avaliados foram: Adequação ao tema proposto; Emprego de recursos e elementos literários; Criatividade; e Uso correto da Língua Portuguesa. Para cada critério, a Comissão Organizadora elaborou perguntas com o intuito de auxiliar o processo de avaliação, criando uma ficha de avaliação. A cada pergunta, o(a) avaliador(a) atribuía uma nota de 0 a 10, onde a nota mínima é 0 e a máxima é 10. No Quadro 1, são apresentadas as perguntas relacionadas a cada critério.

Quadro 1 - Ficha de Avaliação Detalhada

\begin{tabular}{|l|l|}
\hline Critério & Pergunta \\
\hline $\begin{array}{l}\text { Adequação ao Tema } \\
\text { Proposto (A) }\end{array}$ & P1: A obra está adequada ao tema proposto? \\
\hline $\begin{array}{l}\text { Emprego de Recursos e } \\
\text { Elementos Literários (E) }\end{array}$ & $\begin{array}{l}\text { P2: A obra possui elementos que enriquecem a leitura e a } \\
\text { imaginação do leitor, como, por exemplo, figuras de palavra, figuras } \\
\text { de pensamento, figuras de construção, figuras de som, pontuação } \\
\text { bem colocada que proporcione expressividade a obra literária? }\end{array}$ \\
\hline $\begin{array}{l}\text { Uso correto da Língua } \\
\text { Portuguesa (U) }\end{array}$ & $\begin{array}{l}\text { P3: A obra foi escrita corretamente segundo as normas da Língua } \\
\text { Portuguesa? }\end{array}$ \\
\hline
\end{tabular}


Motus - Movimento Literário Digital: despertando e divulgando a literatura nacional

\begin{tabular}{|l|l|}
\hline Criatividade $(\mathrm{C})$ & P4: A obra possui uma ideia original? \\
& P5: A obra possui pensamentos bem elaborados e intrigantes? \\
& P6: A obra possui versos, parágrafos ou diálogos escritos de forma \\
que despertam curiosidade no leitor?
\end{tabular}

Fonte: produção autoral

Os avaliadores tiveram o prazo de 2 semanas para julgar as obras e retornar as fichas de avaliação preenchidas para a Comissão Organizadora, que teve a responsabilidade de calcular a nota final de cada obra.

A nota da obra por avaliador (NA) foi formada pela média aritmética simples da nota obtida em cada um dos critérios. Quando o critério possuía mais de uma pergunta, como é o caso do critério Criatividade, a sua nota era computada através da média aritmética simples das notas de suas perguntas. A nota final da obra (NF) era composta pela média aritmética simples das notas atribuídas por cada um dos três avaliadores. As fórmulas adotadas no processo de seleção das obras estão organizadas no Quadro 2.

Após o cálculo da nota de todas as obras avaliadas, a Comissão Organizadora contabilizou as vinte melhores notas e divulgou a seleção final. Então, a primeira edição da Motus começou a ser diagramada.

Quadro 2 - Fórmulas utilizadas na seleção das obras

\begin{tabular}{|l|l|}
\hline Objetivo & Fórmula \\
\hline Calcular Critério Criatividade C & (Nota P4 + Nota P5 + Nota P6)/3 \\
\hline Calcular a nota da obra por um avaliador NA & $(\mathrm{A}+\mathrm{E}+\mathrm{U}+\mathrm{C}) / 4$ \\
\hline Calcular a nota final da obra NF & (NA1 + NA2 +NA3)/3 \\
\hline
\end{tabular}

Fonte: produção autoral

No total, a Motus \#1 possui 55 páginas, contando, além das 20 obras literárias selecionadas, com ilustrações, editorial, sumário e agradecimento. As ilustrações foram criadas pelos artistas gráficos Amanda Fagundes Gobus Lopes, Huillian Eduardo Serpa e João Então ${ }^{1}$ com intuito de representar graficamente as obras literárias selecionadas. A revista foi hospedada

\footnotetext{
${ }^{1}$ Nome artístico de João Sampaio.
} 
na plataforma de publicação Issuu (ISSUU, 2017) e, de acordo com essa plataforma, a Motus \#1 foi lida 1085 vezes desde a data de sua publicação (30/06/2017) até 01 de outubro de 2018.

Após a produção da Motus \#1, a Comissão Organizadora teve como tarefa a divulgação da revista literária digital. Assim, o aplicativo QuizMotus foi desenvolvido, a fim de atrair mais leitores para a revista, proporcionando uma interação lúdica com as obras selecionadas. A Figura 1 apresenta duas das perguntas presentes no aplicativo.

O aplicativo foi apresentado ao público durante a $38^{a}$ Feira do Livro de Alegrete, com o intuito de estimular a leitura da Motus \#1 entre os visitantes da feira. Além disso, ele também foi apresentado aos convidados do Coquetel de Lançamento da Motus, evento realizado para a divulgar a Motus e agradecer as Comissões que trabalharam para o desenvolvimento dessa ação.

\section{RESULTADOS E ANÁLISES}

A ação de extensão Motus, em sua primeira edição, obteve um total de 125 inscritos. Sendo 32 obras inscritas na modalidade Conto e 93 obras na modalidade Poema. No Gráfico 1, é apresentada a relação de inscritos por localização. Conforme pode ser observado neste gráfico, a primeira edição da Motus obteve inscrições de 14 estados distintos e do Distrito Federal. O estado com mais participantes foi o Rio Grande do Sul, com 46 inscritos. A grande participação desse estado deu-se pela divulgação presencial promovida pela Comissão Organizadora nas escolas e junto à comunidade Alegretense. $\mathrm{O}$ segundo estado com mais inscritos foi Rio de Janeiro, com 22 inscritos e, em terceiro lugar, São Paulo, com 21 inscritos.

Figura 1 - Interface do App QuizMotus

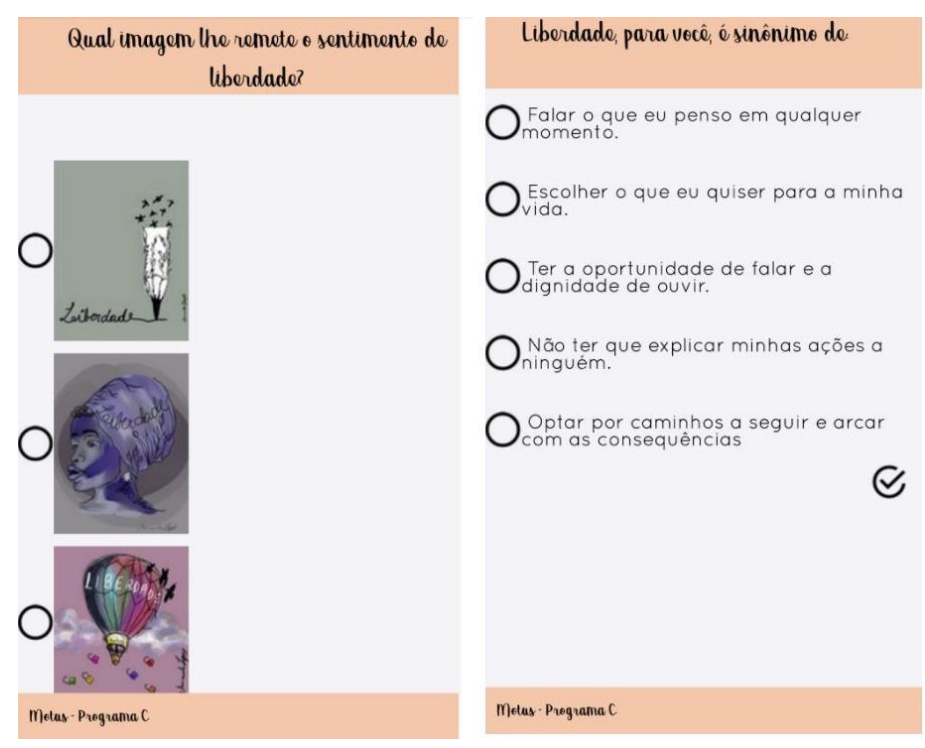

Fonte: produção autoral 
Gráfico 1 - Obras recebidas por localização

Inscritos por Localizaçāo
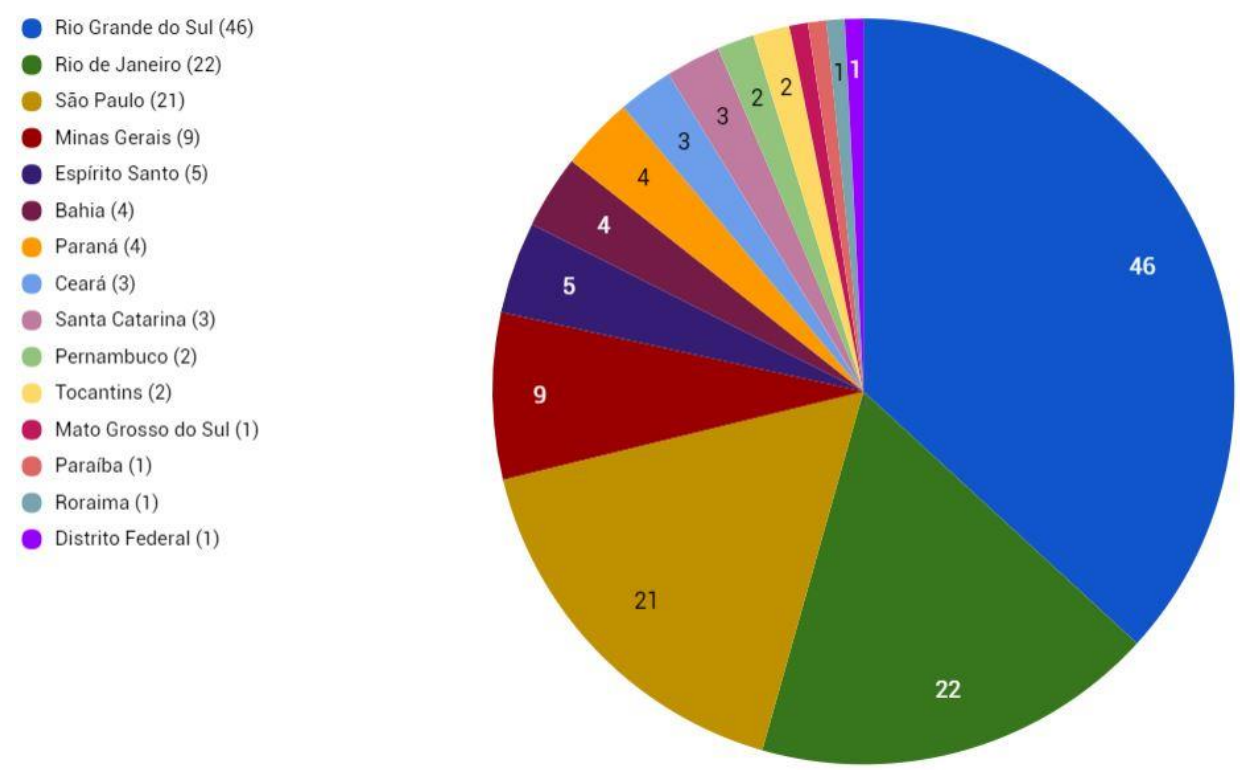

Fonte: produção autoral

Após a triagem das 125 obras realizada pela Comissão Organizadora, ocorreu a avaliação das 82 obras aptas, conduzida pela Comissão Avaliadora. Então, 20 obras literárias foram selecionadas para integrar a primeira edição da Motus. No Gráfico 2, é apresentada a quantidade de obras selecionadas por localização. Conforme pode ser observado no Gráfico 2, os três estados com mais obras selecionadas são os mesmos estados com mais inscritos.

Gráfico 2 - Obras Selecionadas por Localização

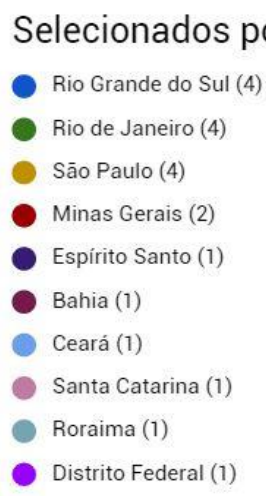




\section{CONSIDERAÇÕES FINAIS}

A ação de extensão Motus foi elaborada com grandes anseios. Desde seu ambicioso prelúdio, foi desejado que a ação tivesse porte nacional, inspirasse a população brasileira a expressar sobre seus ideais em prosa e verso e, além disso, que sua aparência fosse criativa e única.

Com muitas reuniões, esforço coletivo e horas de planejamento, é possível afirmar que os anseios concebidos foram realizados e o produto final, de fato, reflete o trabalho em conjunto e a dedicação que todos os integrantes forneceram para a realização dessa ação.

Todavia, em edições futuras alguns pontos ainda serão trabalhados. Entre eles, sua divulgação no meio acadêmico brasileiro. Portanto, formas de inserção da Motus em outras Universidades e Escolas Brasileiras têm sido estudadas.

Além disso, ressalta-se que o tempo de criação da revista foi relativamente extenso pelo fato de ser sua primeira edição. Assim, acredita-se que em edições futuras algumas atividades serão realizadas mais rapidamente, como, por exemplo, o desenvolvimento do edital, atividade que foi concretizada em 5 reuniões na primeira edição e, possivelmente, nas demais edições serão necessárias, no máximo, 2 reuniões para realizá-la.

Outro ponto marcante foi o pedido de pessoas interessadas para que as próximas edições da Motus fossem abertas não só ao público brasileiro, mas a todos os Países Lusófonos. Todas as contribuições feitas por inscritos, membros de Comissões e público em geral foram contempladas na segunda edição (Motus \#2), assim esperamos que a Motus ganhe mais visibilidade e reconhecimento, continuando a valorizar a literatura de artistas amadores.

\section{REFERÊNCIAS}

GOOGLE. Termos de Serviço do Google Play. Disponível em <https://play.google.com/intl/pt-BR br/about/play-terms.html> Acesso em 28. set. 2018.

VIEIRA, Aline. Motus \#1. Universidade Federal do Pampa, 2017. Disponível em: <https://issuu.com/motus-unipampa/docs/motus 1>. Acesso em 28. set. 2018.

QUIZMOTUS. QuizMotus. Programa C, 2017. Disponível em: $<$ https://play.google.com/store/apps/details?id=edu.unipampa.br.motusquiz\&hl=pt BR $>$.

Acesso em 28. set. 2018.

EDITAL MOTUS. Motus - Movimento Literário Digital - Edital $\mathbf{n}^{\mathbf{0}}$ 01/2017. Programa C, 2017. Disponível em: < https://docs.google.com/document/d/11PyUYPkarH5ieMmPwI582li6 mYxfgIS4yKp6G3rWceQ/pub>. Acesso em 28. set. 2018. 
Motus - Movimento Literário Digital: despertando e divulgando a literatura nacional

SCRIBUS. Scribus - Open Source Desktop Publishing. The Scribus Team, 2016. Disponível em: < https://www.scribus.net>. Acesso em 28. set. 2018.

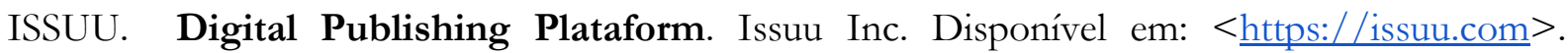
Acesso em 28. set. 2018.

Recebido em: 26/03/2018

Aceito em: 10/10/2018 